\title{
RELATIONSHIP BETWEEN BLOOD CHOLESTEROL AND INCREASED METABOLISM FROM DINITROPHENOL AND THYROID ${ }^{1}$
}

\author{
By W. C. CUTTING, D. A. RYTAND and M. L. TAINTER \\ (From the Departments of Medicine and of Pharmacology, Stanford University
} School of Medicine, San Francisco)

(Received for publication February 13, 1934)

It has long been known that certain manifestations of hyperthyroidism follow directly upon the increased metabolic rate, but the causes of other changes in the disease are not so obvious. Dinitrophenol increases metabolism by a peripheral action in the tissues, and apparently has no other concomitant actions in therapeutic doses (1 to 10); thus it is available for studying isolated effects of increased metabolism and determining the importance of the latter in thyrotoxicosis.

Anxiety, palpitation, and tremor, which are commonly found in hyperthyroidism, are absent when the metabolism is correspondingly increased by dinitrophenol, but increased perspiration and sensations of warmth are present in both (7). The latter symptoms, therefore, are apparently due directly to the heightened metabolism. Another difference from thyroid or thyroxine (6) is absence of accelerated metamorphosis of tadpoles. The heightened metabolism caused by excess thyroid is associated with an increased pulse pressure, while that of dinitrophenol is not accompanied by an increased output, as judged from pulse pressure-pulse rate formulae. However, some change in output can be demonstrated in experimental animals with metabolic rates beyond those seen clinically (8). Apparently, with dinitrophenol the tissues get their greater oxygen supply, at least partly, by increased deoxygenation of the blood. In our experience after dinitrophenol, and after dinitro-o-cresol (19), patients with severe degrees of hypothyroidism fail to get symptomatic relief even though the metabolic rate is restored to normal by these drugs. Thus, the ability to increase metabolism appears to be the only common action of dinitrophenol and thyroid so far studied.

This paper deals with a blood-constituent which is quantitatively modified in thyroid disease, namely, cholesterol. The concentration of blood cholesterol is usually raised in hypothyroidism, and lowered slightly in hyperthyroidism. Therefore, we have studied the changes in cholesterol after dinitrophenol medication to determine whether it varies with the meta-

${ }^{1}$ Supported in part by a grant from the Rockefeller Fluid Research Fund of the School of Medicine, Stanford University. 
bolic rate per se, or with some other factor present in thyroid excess or deficiency.

\section{THE RELATIONSHIP BETWEEN THYROID CONTROLLED METABOLISM AND BLOOD CHOLESTEROL}

Many reports have been made on the relationship of basal metabolic rates to blood cholesterol concentrations, with agreement that there is an inverse relationship between these two variables. The published data (11 to 15) have been treated by standard statistical methods (16) and the regression curve of cholesterol on basal metabolic rate from these 205 cases is presented in Figure 1.

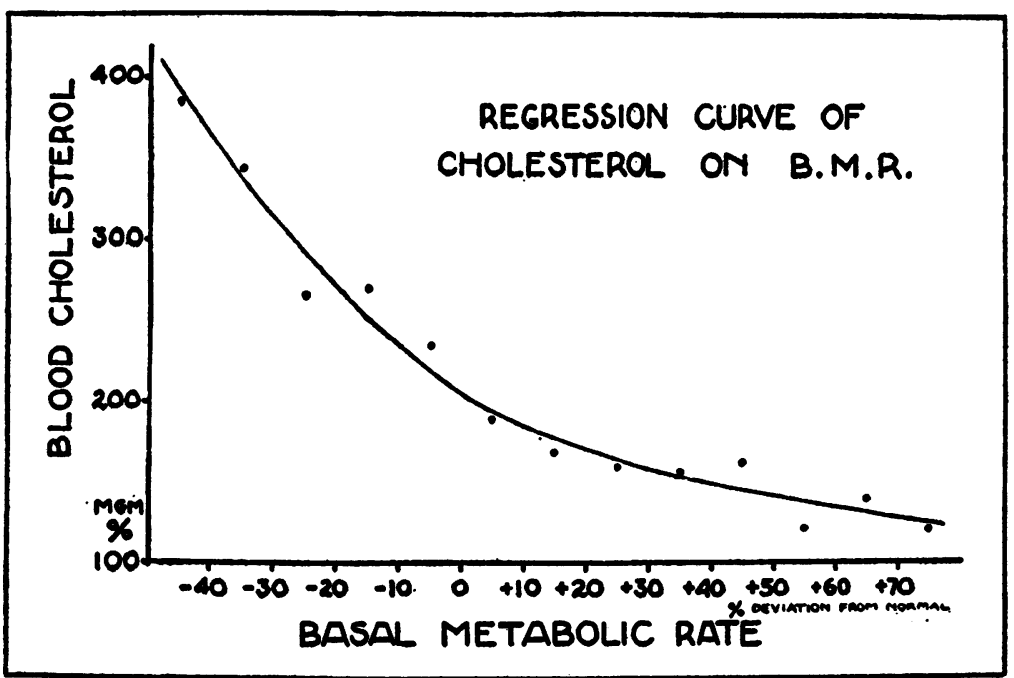

Fig. 1. The Relationship between Blood Cholesterol and Basal Metabolic Rate, as Reported in the Literature

The number of observations represented by each point in the figure are:

\begin{tabular}{r|r|r|r|r|r|r|r|r|r|r|r|r|r}
\hline Basal metabolic rate. & -40 & -30 & -20 & -10 & 0 & +10 & +20 & +30 & +40 & +50 & +60 & +70 & +80 \\
\hline $\begin{array}{r}\text { Number of observa- } \\
\text { tions.............. }\end{array}$ & 4 & 6 & 15 & 15 & 20 & 14 & 21 & 20 & 21 & 16 & 16 & 17 & 12 \\
\hline
\end{tabular}

For this curve, the correlation coefficient is $-0.568 \pm 0.032$ and the correlation ratio $-0.754,(20)$.

Although the cholesterol-determinations were made by various methods, which perhaps accounts for rather high cholesterol values for any given metabolism, the curve nevertheless indicates the presence of a significant, inverse, curvilinear correlation between the two variables. A more recent 
study of a large number of cases by Hurxthal (18) likewise illustrates this correlation.

\section{THE RELATIONSHIP OF DINITROPHENOL-CONTROLLED METABOLISM} AND BLOOD CHOLESTEROL

Twenty-eight sets of observations were made on 23 subjects, five of the subjects being studied on two separate occasions. Nineteen subjects had initially normal basal metabolic rates, and were clinically either normal or obese. The remaining subjects had basal metabolic rates below -15 per cent, and were clinically either hypothyroid or obese, or both. In each case, control estimations of blood cholesterol and basal metabolism were made, and then dinitrophenol was given for periods of from one to thirteen weeks, when the metabolism and blood cholesterol were again estimated.

No attempt was made to secure uniformity of diet for the subjects, and in about one third of the cases the blood cholesterol estimations were not made from fasting samples. Basal metabolic rates were all determined under standard conditions and no dinitrophenol was given for 24 hours before the test. Inasmuch as we have shown (3) that within this period of time there is a considerable recovery from the metabolic stimulation of dinitrophenol, the recorded metabolic rates are somewhat lower than the average rates that were actually maintained in these patients. The drug was administered as the sodium dinitrophenol (2-4 or alpha) in daily oral doses of from 100 to $400 \mathrm{mgm}$. Cholesterols of the venous blood were determined by the colorimetric method of Bloor, as modified by Sackett (17), and expressed as mgm. per $100 \mathrm{cc}$. of blood.

In Table $I$ are presented the results obtained, grouped according to initial metabolic rates. In the group of patients whose metabolic rates before medication were above -15 per cent, the mean basal metabolic rate during the control period was -5.1 per cent, and the cholesterol concentration $156 \pm 4.55 \mathrm{mgm}$. per cent. After dinitrophenol, the mean basal metabolic rate rose 25.1 per cent, or to a level of +20.0 per cent, and the mean cholesterol was $170 \pm 5.18 \mathrm{mgm}$. per cent. This change of +14 $\pm 6.9 \mathrm{mgm}$. per cent in cholesterol is not statistically significant, and is in contrast to the fall of $50 \mathrm{mgm}$. per cent which would be expected from Figure 1.

In the group of patients whose initial metabolic rates were below -15 per cent, the mean basal metabolic rate during the control period was - 22.6 per cent, and the blood cholesterol $150 \pm 7.60 \mathrm{mgm}$. per cent. After administration of the drug, the mean basal metabolic rate rose 35.1 per cent, or to a level of +12.5 per cent, and the cholesterol was $142 \pm 9.04$ mgm. per cent. This change in cholesterol of $-8 \pm 11.8 \mathrm{mgm}$. per cent again is not statistically significant, and is in contrast with the fall of 100 mgm. per cent which would be expected from Figure 1. "It is interesting to note that in these two groups of patients, those with the initially low meta- 
TABLE I

Changes in metabolic rate and blood cholesterol in patients receiving dinitrophenol

\begin{tabular}{|c|c|c|c|c|c|c|c|c|}
\hline \multirow{2}{*}{$\begin{array}{l}\text { Patient } \\
\text { number }\end{array}$} & \multicolumn{2}{|c|}{ Treatment } & \multicolumn{3}{|c|}{ Basal metabolism } & \multicolumn{3}{|c|}{ Cholesterol } \\
\hline & Duration & Daily dose & Before & After & Change & Before & After & Change \\
\hline & weeks & $m g m$. & per cent & per cent & per cent & $\begin{array}{l}\text { mgm. per } \\
100 \text { cc. }\end{array}$ & $\begin{array}{l}\text { mgm. per } \\
100 \mathrm{cc.}\end{array}$ & $\begin{array}{l}\text { mgm. per } \\
100 \text { cc. }\end{array}$ \\
\hline & \multicolumn{8}{|c|}{ Subjects with normal basal metabolic rates } \\
\hline $\begin{array}{r}1 \\
2 \\
3 \\
4 \\
4 \\
5 \\
6 \\
7 \\
8 \\
9 \\
10 \\
11 \\
11 \\
12 \\
13 \\
14 \\
15 \\
16 \\
17 \\
18 \\
19\end{array}$ & \begin{tabular}{r|}
1 \\
1 \\
1 \\
1 \\
2 \\
2 \\
2 \\
2 \\
2 \\
2 \\
2 \\
2 \\
2 \\
2 \\
3 \\
4 \\
4 \\
5 \\
6 \\
6 \\
10 \\
13
\end{tabular} & $\begin{array}{c}300 \\
“ \\
“ \\
“ \\
“ \\
“ \\
“ \\
“ \\
“ \\
“ \\
“ \\
200-300 \\
100-300 \\
200-400 \\
200-400\end{array}$ & $\begin{array}{r}-7 \\
+7 \\
\\
-9 \\
-9 \\
0 \\
-10 \\
-6 \\
-4 \\
-5 \\
+7 \\
-11 \\
-7 \\
+8 \\
-9 \\
-9 \\
-10 \\
-12 \\
\end{array}$ & $\begin{array}{l}+33 \\
+50 \\
\\
+30 \\
+30 \\
+36 \\
+8 \\
+45 \\
+30 \\
+45 \\
+51 \\
-1 \\
+2 \\
-9 \\
0 \\
-8 \\
-12 \\
+11 \\
\end{array}$ & $\begin{array}{l}+40 \\
+43 \\
\\
+39 \\
+39 \\
+36 \\
+18 \\
+51 \\
+34 \\
+50 \\
+44 \\
+10 \\
+9 \\
-17 \\
+9 \\
+1 \\
+2 \\
+23 \\
\end{array}$ & $\begin{array}{l}157 \\
125 \\
146 \\
166 \\
161 \\
161 \\
140 \\
125 \\
125 \\
125 \\
135 \\
136 \\
235 \\
172 \\
150 \\
140 \\
150 \\
208 \\
208 \\
\end{array}$ & $\begin{array}{l}176 \\
142 \\
163 \\
171 \\
171 \\
184 \\
158 \\
158 \\
150 \\
162 \\
150 \\
150 \\
235 \\
209 \\
100 \\
120 \\
192 \\
247 \\
190 \\
\end{array}$ & $\begin{array}{r}+19 \\
+17 \\
+17 \\
+5 \\
+10 \\
+23 \\
+18 \\
+33 \\
+25 \\
+37 \\
+15 \\
+14 \\
0 \\
+37 \\
-50 \\
-20 \\
+42 \\
+39 \\
-18 \\
\end{array}$ \\
\hline \multirow{2}{*}{19} & \multicolumn{3}{|c|}{ Mean $=\overline{-5.1}$} & +20.0 & +25.1 & 156 & 170 & +14 \\
\hline & \multicolumn{8}{|c|}{ Subjects with basal metabolic rates below -15 per cent } \\
\hline $\begin{array}{l}20 \\
21 \\
22 \\
23 \\
24 \\
25 \\
26 \\
27 \\
28\end{array}$ & $\begin{array}{r}2 \\
2 \\
4 \\
4 \\
4 \\
5 \\
6 \\
8 \\
10 \\
12\end{array}$ & $\begin{array}{c}300 \\
" \\
“ \\
1 " \\
100-200 \\
100-300 \\
300 \\
" ، \\
“\end{array}$ & $\begin{array}{l}-24 \\
-30 \\
-20 \\
-17 \\
-16 \\
-21 \\
-16 \\
-28 \\
-24\end{array}$ & $\begin{array}{l}+23 \\
-13 \\
+20 \\
+5 \\
+22 \\
+34 \\
-4\end{array}$ & $\begin{array}{l}+47 \\
+17 \\
+40 \\
+21 \\
\\
+38 \\
+62 \\
+20\end{array}$ & $\begin{array}{r}140 \\
193 \\
210 \\
120 \\
150 \\
90 \\
144 \\
160 \\
140\end{array}$ & $\begin{array}{r}150 \\
225 \\
192 \\
100 \\
125 \\
90 \\
136 \\
130 \\
130\end{array}$ & $\begin{array}{r}+10 \\
+32 \\
-18 \\
-20 \\
-25 \\
0 \\
-8 \\
-30 \\
-10\end{array}$ \\
\hline \multicolumn{4}{|c|}{ Mean $=\overline{-22.6}$} & +12.5 & +35.1 & 150 & 142 & -8 \\
\hline \multicolumn{4}{|c|}{ Mean for entire series $=-10.8$} & +17.8 & +28.0 & 153 & 161 & +6.9 \\
\hline
\end{tabular}

bolic rates showed a greater increase in metabolism than those with the normal rates, although their average dose was no higher. While the series may not be large enough to give a statistical certainty to this conclusion, yet it indicates that low metabolic rates may be increased by dinitrophenol probably as readily as normal rates. 


\section{DISCUSSION}

It is perhaps not sufficiently emphasized in clinical literature and textbooks that the symptoms of hyperthyroidism fall into at least two distinct categories, the one a metabolic stimulation, and the other a stimulation of the sympathetic nervous system. As a result of the increase in metabolism, hyperthyroid patients have the symptoms of increased perspiration, sensations of warmth, and a tendency to be dyspneic on unusual exertion. These follow directly from the increased metabolic rate, and may also be seen in patients receiving dinitrophenol. The sympathetic symptoms of hyperthyroidism include cardiac instability, vasomotor changes. tremor and nervous manifestations. These are not induced by dinitrophenol, even though the metabolic levels be abnormally high. It would follow that these changes are not secondary to the metabolic stimulation of thyroid, but are a separate and quite independent action of the hormone. Dinitrophenol therefore reproduces the metabolic stimulation but not the sympathetic or other actions of the thyroid secretion.

As pointed out before, dinitrophenol also does not possess the stimulant power of thyroid for metamorphosis in amphibia, which would indicate that this growth change also is not conditioned by the metabolic level. The present paper deals with still another thyroid manifestation, the level of blood cholesterol. Our observations show that this also is not controlled by the metabolic rate, but rather by the other actions of thyroid secretion.

These facts serve to illustrate again that the physiological actions of thyroid concern many functions which are not dependent upon the general metabolic level. In fact, there is no evidence at present that dinitrophenol can exert any of the " hormonal" actions of thyroid secretion, even though it is a powerful metabolic stimulant.

\section{CONCLUSIONS}

1. From previously reported data, a significant correlation between basal metabolic rate and blood cholesterol concentration has been established for human subjects.

2. This correlation was not present when the metabolism was raised by dinitrophenol.

3. Therefore, the changes in blood cholesterol present in thyroid disease are not related directly to the metabolic rate, but to other actions of thyroid secretion.

4. The stimulation of metabolism by dinitrophenol was as great in patients with initial metabolic rates below -15 per cent as it was in those with higher rates, which indicates that the drug may increase depressed as well as normal metabolism. 


\section{BIBLIOGRAPHY}

1. Cutting, W. C., and Tainter, M. L., Actions of dinitrophenol. Proc. Soc. Exper. Biol. and Med., 1932, 29, 1268.

2. Tainter, M. L., Boyes, J. H., and DeEds, F., Actions of dinitrophenol in diabetic dogs. Arch. internat. de pharmacodyn. et de thérap., 1933, 45, 235.

3. Cutting, W. C., Mehrtens, H. G., and Tainter, M. L., Actions and uses of dinitrophenol. Promising metabolic applications. J. A. M. A., 1933, 101, 193.

4. Tainter, M. L., and Cutting, W. C., Febrile, respiratory and some other actions of dinitrophenol. J. Pharmacol. and Exper. Therap., 1933, 48, 410.

5. Tainter, M. L., and Cutting, W. C., Miscellaneous actions of dinitrophenol. Repeated administrations, antidotes, fatal doses, antiseptic tests and actions of some isomers. J. Pharmacol. and Exper. Therap., 1933, 49, 187.

6. Cutting, C. C., and Tainter, M. L., Comparative effects of dinitrophenol and thyroxin on tadpole metamorphosis. Proc. Soc. Exper. Biol. and Med., 1933, 31, 97.

7. Tainter, M. L., Stockton, A. B., and Cutting, W. C., Use of dinitrophenol in obesity and related conditions. J. A. M. A., 1933, 101, 1472.

8. Hall, V. E., Field, J., Sahyun, M., Cutting, W. C., and Tainter, M. L., Carbohydrate metabolism, respiration and circulation in animals with basal metabolism heightened by dinitrophenol. Am. J. Physiol., 1933, $106,432$.

9. Emge, L. A., Wulff, L. M. R., and Tainter, M. L., Effects of dinitrophenol on an experimental sarcoma of the white rat. Proc. Soc. Exper. Biol. and Med., 1933, 31, 152.

10. Cutting, W. C., and Tainter, M. L., Metabolic actions of dinitrophenol with the use of balanced and unbalanced diets. J. A. M. A., 1933, 101, 2099.

11. Mason, R. L., Hunt, H. M., and Hurxthal, L., Blood cholesterol values in hyperthyroidism and hypothyroidism-their significance. New England J. Med., 1930, 203, 1273.

12. Epstein, A. A., and Lande, H., Studies on blood lipoids. I. The relation of cholesterol and protein deficiency to basal metabolism. Arch. Int. Med., 1922, 30, 563.

13. Nicholls, E. G., and Perlzweig, W. A., The plasma fats and the iodine absorption capacity of the fatty acids in hyperthyroidism. J. Clin. Invest., 1928, 5, 195.

14. Gardner, J. A., and Gainsborough, $H$., The relationship of plasma cholesterol and basal metabolism. Brit. Med. J., 1928, 2, 935.

15. Hinton, J. W., The adrenalin test and cholesterol determination in the diagnosis of borderline hyperthyroidism. Am. J. M. Sc., 1930, 180, 681.

16. Pearl, R., Introduction to Medical Biometry and Statistics. W. B. Saunders and Co., Philadelphia, 1930, 2d ed.

17. Sackett, G. E., Modification of Bloor's method for the determination of cholesterol in whole blood or blood serum. J. Biol. Chem., 1925, 64, 203.

18. Hurxthal, L. M., Blood cholesterol in thyroid disease. I. Analysis of findings in toxic and in nontoxic goiter before treatment. Arch. Int. Med., 1933, 51, 22.

19. Dodds, E. C., and Robertson, J. D., The clinical applications of dinitro-ocresol. Lancet, 1933, 2, 1197.

20. Rytand, D. A., The rate of excretion of urine in subjects with different amounts of renal tissue. J. Clin. Invest., 1933, 12, 1153. 